\title{
Projeto e Desenvolvimento de um redator automático de atas de reunião, acionado por comando de voz
}

\section{Design and Development of an automatic meeting minutes editor, powered by a voice command}

Darllan da Costa Ribeiro1, Jade Diane Fernandes Targino Filgueira², Vinícius Vieira de Araújo $^{3}$, Luís Felipe Santos Oliveira ${ }^{4}$, Mateus Dall'Agnol ${ }^{5}$, Walisson Pereira de Sousa 6

\section{RESUMO}

O Projeto de Desenvolvimento do Produto - PDP, é um processo que facilita a produção das especificações de um determinado produto. Logo, a proposta deste trabalho foi a de utilizar os fundamentos do PDP para auxiliar no projeto de um equipamento capaz de redigir atas de reunião de forma automática por meio do acionamento por comando de voz. Para tanto, foram realizados pesquisas com público específico para identificar requisitos dos potenciais clientes para o projeto. De modo geral, foram apontados que o produto deve ser leve, de pequeno porte e que tenha confiabilidade em suas funções, principalmente, a de transcrever voz para texto. A partir disso, foi possível a idealização de um equipamento capaz de formular atas de reunião por meio do comando de voz exportando para o computador em formato docx através do software do produto.

Palavras-chave: Projeto e Desenvolvimento de Produtos; Desdobramento da Função Qualidade; Análise dos Modos de Falhas e Efeitos.

\section{ABSTRACT}

The Product Design and Development, is a process that facilitates the production of the specifications of a given product. Therefore, the proposal of this work was to use the fundamentals of this process to assist in the design of an equipment capable of writing meeting minutes automatically through voice command. In order to do so, we conducted surveys with specific audiences to identify requirements of potential customers for the project. In general, it was pointed out that the product should be light, small and reliable in its functions, mainly to transcribe voice to text. From this, it was possible to idealize an equipment capable of formulating meeting through voice command exporting to the computer in docx format through the product software.

Keywords: Product Design and Development; Quality Function Deployment; Failure Modes and Effects Analysis.
${ }^{1}$ Graduando em Gestão da Produção Industrial - IFTO.

E-mail: darllanyuri@gmail.com

2 Mestre em Ciência

Engenharia dos Materiais IFTO.

${ }^{3}$ Graduando em Análise e Desenvolvimento de Sistemas - IFTO.

${ }^{4}$ Graduando em Análise e Desenvolvimento de Sistemas - IFTO.

${ }^{5}$ Mestre em Engenharia de Produção e Sistemas - IFTO.

${ }^{6}$ Mestre em Ciências da Computação - IFTO. 


\section{INTRODUÇAOO}

Projeto de Desenvolvimento do Produto (PDP), é o processo pelo qual uma organização transforma dados acerca das oportunidades de mercado e possibilidades tecnológicas em informações vantajosas para a fabricação de um produto (CLARK e FUJIMOTO, 1991). Dessa forma, o PDP é capaz de auxiliar no complexo processo de criação de novos produtos fornecendo diretrizes que orientam e organizam suas etapas.

Segundo Abreu (2007), para iniciar o processo de projeto de um novo produto deve-se buscar possibilidades e restrições tecnológicas, considerando as estratégias competitivas, chegando-se assim às especificações de projeto de um produto e de seu processo de produção, para que a manufatura seja capaz de produzi-lo. O ATAEASY foi idealizado a partir de uma demanda existente entre os servidores de uma Instituição de Ensino Superior (IES) pertencente à rede Federal, localizada na cidade de Araguaína no Estado do Tocantins - TO. Durante entrevistas realizadas, os mesmos relataram que o trabalho de redação de atas era repetitivo e maçante e que teriam interesse na utilização de um dispositivo que fosse capaz de agilizar esse processo. Essa foi a inspiração que motivou a proposta de desenvolvimento do ATAEASY.

A matriz Quality Function Deployment (QFD), ou seja desdobramento da função de qualidade foi utilizada no projeto do produto para facilitar a especificação das funcionalidades do equipamento, sendo uma ferramenta útil que, segundo Cheng (1995), é aplicável através de matrizes com o intuito de desdobrar as necessidades dos clientes e os requisitos técnicos relacionados a ela em especificações técnicas para um determinado produto.

Outra ferramenta utilizada para garantir o bom andamento do projeto do produto em questão foi a Failure Mode and Effect Analysis (FMEA) ou análise dos modos de falhas e efeitos. Em consonância com Zorzan et al. (2013) o qual diz que a FMEA é uma ferramenta utilizada para aumentar a confiabilidade de um produto durante a fase de projeto ou processo, evitando possíveis problemas.

Portanto o objetivo desse trabalho é criar um equipamento que possa redigir atas de maneira automática por meio do comando de voz e exportando texto para o computador em formato editável (docx). Este produto será capaz de: auxiliar na elaboração de atas de maneira mais rápida e eficiente; padronização de componentes básicos como cabeçalhos, terminologia e cronologia das atas; Redução do tempo de lançamento e reparos após o lançamento. 


\section{MATERIAIS E METODOS}

A primeira etapa desta pesquisa foi planejada tendo como perspectiva a abordagem de análise qualitativa, que tem como característica a construção da realidade, ou seja, procurar as pessoas para saber as suas necessidades específicas. Sendo assim, métodos qualitativos abrangem pesquisas percebidas como um ato subjetivo de construção de ideias para formar um único produto que supra a necessidade do cliente (GÜNTHER, 2006).

Nessa etapa, produzimos uma pesquisa informal por meio de uma interlocução com alguns funcionários do Campus-Araguaína do Instituto Federal do Tocantins (IFTO). Os entrevistados foram indagados a respeito de eventuais dificuldades na execução das tarefas diárias. Identificou-se que muitos dos servidores consultados se queixavam da tarefa de elaborar atas de reunião. Ao constatar que essa era uma reclamação recorrente, dentre os entrevistados, optou-se por utilizá-la como oportunidade de negócio motivadora para o projeto.

Visando a resolução do problema identificado, foram feitas observações de como funciona o atual processo de fabricação de atas de reunião. Para isso, um dos membros do presente estudo se disponibilizou a atuar como secretário de algumas reuniões, se tornando responsável pela elaboração das atas. A próxima etapa consistiu em realizar uma pesquisa de anterioridade tecnológica para que pudéssemos verificar que o produto idealizado era realmente inovador, para isso foi feita uma busca nos periódicos e anais da área e buscas em bancos de patentes.

Foram consultados 2 bancos de patentes, um nacional e um internacional, respectivamente o Instituto Nacional de Pesquisa e Indústria (INPI) e o Escritório Europeu de Patentes (ESPACENET). Verificou-se na pesquisa de anterioridade, que não houve nenhum produto relacionado ao ATAEASY.

Depois da pesquisa de anterioridade, partiu-se para a etapa de levantamento de requisitos. Para essa etapa da pesquisa, a metodologia escolhida foi uma pesquisa survey de natureza exploratória. Foi elaborado um questionário em formato eletrônico que foi enviado via e-mail institucional para todos os servidores do campus.

\section{RESULTADOS E DISCUSSÁO}

Para as finalidades desse trabalho será utilizada uma simplificação da metodologia de planejamento do produto proposta por Baxter (2000). Sendo assim, o planejamento do 
redator de atas automático será divido em identificação de uma oportunidade, pesquisa de marketing, análise dos produtos concorrentes e a proposta do novo produto.

\subsection{IDENTIFICAÇÃO DE UMA OPORTUNIDADE}

Pode-se considerar que oportunidades de negócios são situações que auxiliam no desenvolvimento de um produto as quais podem passar a existir quando se pode identificar dois parâmetros, sendo: 1) as demandas e necessidades dos consumidores; 2) diferenças em relação aos produtos oferecidos pelos concorrentes (BAXTER, 2000).

\subsection{PESQUISA DE MARKETING}

Nessa etapa, foi feito um questionário online, com auxílio da ferramenta Google formulários, que foi enviado para todos os servidores do campus, sendo 52 professores e 45 técnicos administrativos, dos quais recebemos 18 respostas. O questionário era composto por 16 perguntas. A primeira pergunta questionava o servidor se ele achava que o ATAEASY ajudaria a diminuir o tempo destinado elaborar atas de reunião. Todos os servidores que responderam o questionário consideraram que sim.

A segunda pergunta questionava ao servidor se ele achava que o ATAEASY poderia ser substituído por um gravador de celular. Dos 15 servidores que responderam essa pergunta, 9 deles responderam que sim, mas apenas um deles justificou sua resposta, afirmando que já existem transcritores de arquivos de áudio muito eficientes. 6 servidores responderam que o produto não poderia ser substituído por um gravador de celular. O Gráfico 1 demonstra os resultados obtidos com as respostas a essa questão.

Gráfico 1: Comparação com a alternativa: gravador de célula
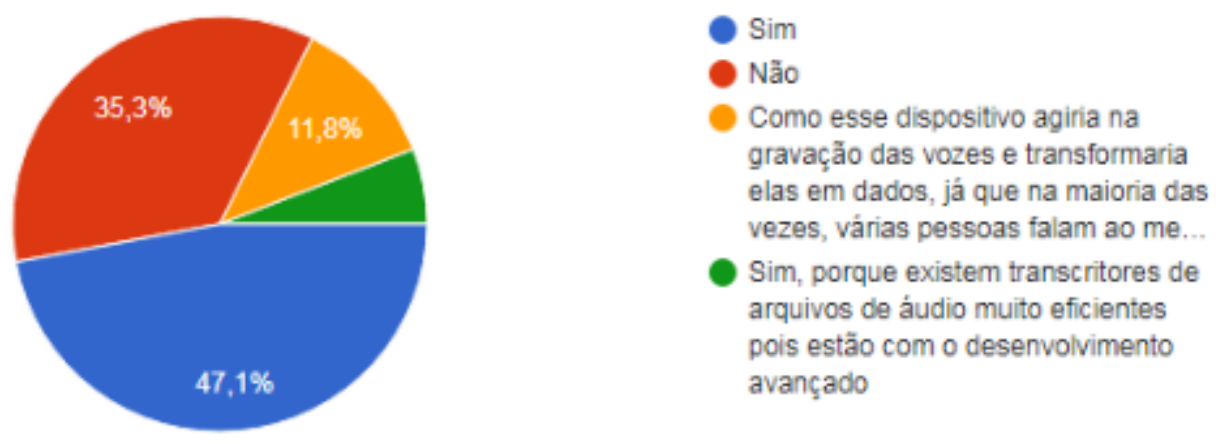

Fonte: Autoria própria. 
Os dados ilustrados pelo Gráfico 1 demonstram que o produto poderia fracassar em vendas, caso viesse a ser desenvolvido comercialmente e que os esforços de marketing do produto precisariam estar fortemente voltados para demonstrar de que maneiras o produto é superior ao uso do gravador de celular.

A terceira pergunta do questionário respondido pelos servidores indagava os mesmos se eles achavam que o ATAEASY poderia ser um produto viável para instituições de ensino como o IFTO. 100\% dos entrevistados concordaram que o projeto tem potencial e pode trazer algum benefício para instituições de ensino como o IFTO, o que indica que o público-alvo seria favorável a utilização do equipamento, caso estivesse disponível na instituição, pois acreditam que o mesmo poderia ajudar a desenvolver de atas de maneira mais rápida e eficaz.

A quarta pergunta do questionário buscava saber dos entrevistados se eles já tinham escutado algo a respeito de algum produto similar ao nosso. Caso afirmativo, perguntamos se eles poderiam indicar onde ou de que maneira ouviram falar do produto.

\section{Gráfico 2: Existência de produtos similares ao ATEASY}

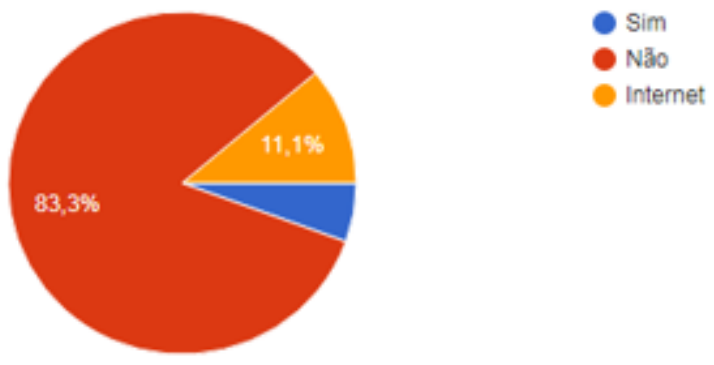

Fonte: Autoria própria

No Gráfico 2, observa-se os dados obtidos com as respostas para a questão de número quatro. Obtivemos 18 respostas, das quais 83,3\% (15 entrevistados) foram negativas, 11,1\% (2 entrevistados) responderam que já ouviram algo semelhante, especificando a internet como fonte da informação e apenas um entrevistado deu indicação de que já viu ou ouviu falar de um produto semelhante sem especificar onde ou como.

A quinta pergunta indagava aos servidores se eles adquirissem o ATAEASY, qual importância eles dariam à característica: Facilidade de utilização. 
Gráfico 3: Facilidade de utilização

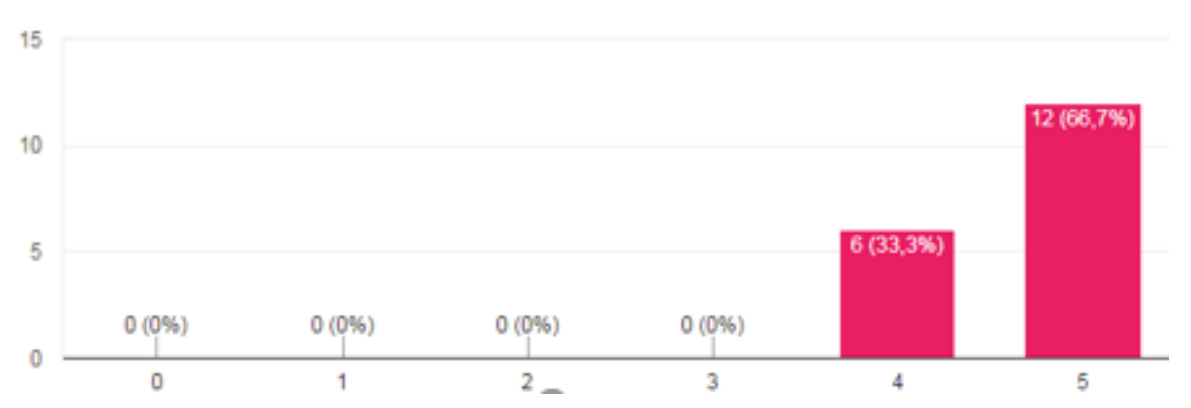

Fonte: Autoria própria

No gráfico 3 , os dados demonstram que os potenciais consumidores dão uma grande importância à característica de facilidade de utilização. Compreendemos com isso que, para o nosso público alvo, mesmo que um produto tenha qualidade, mas sua utilização seja complexa e não intuitiva o mesmo poderia perder competitividade no mercado, pois cerca de $66,7 \%$ dos entrevistados afirmaram que a facilidade de utilização do dispositivo é uma característica extremamente relevante para a qualidade do produto, atribuindo nota 5 na escala de relevância dessa característica ao produto.

A sexta pergunta do questionário respondido pelos servidores indagava sobre a correlação da característica: qualidade da transcrição do comando de voz, com a qualidade do produto.

Gráfico 4: Qualidade da transcrição do comando de voz.

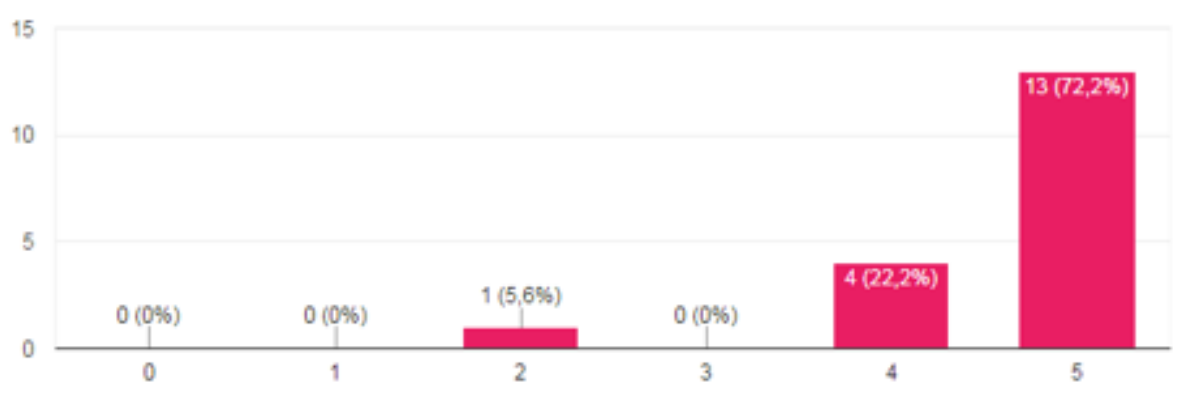

Fonte: Autoria própria.

Vemos nesse gráfico, que $72,2 \%$ dos entrevistados afirmaram que essa característica é extremamente relevante para um redator de atas automático que funciona por meio de comando de voz. 
A sétima pergunta busca descobrir qual importância o cliente daria a característica: Portabilidade do dispositivo.

Gráfico 5: Portabilidade do dispositivo.

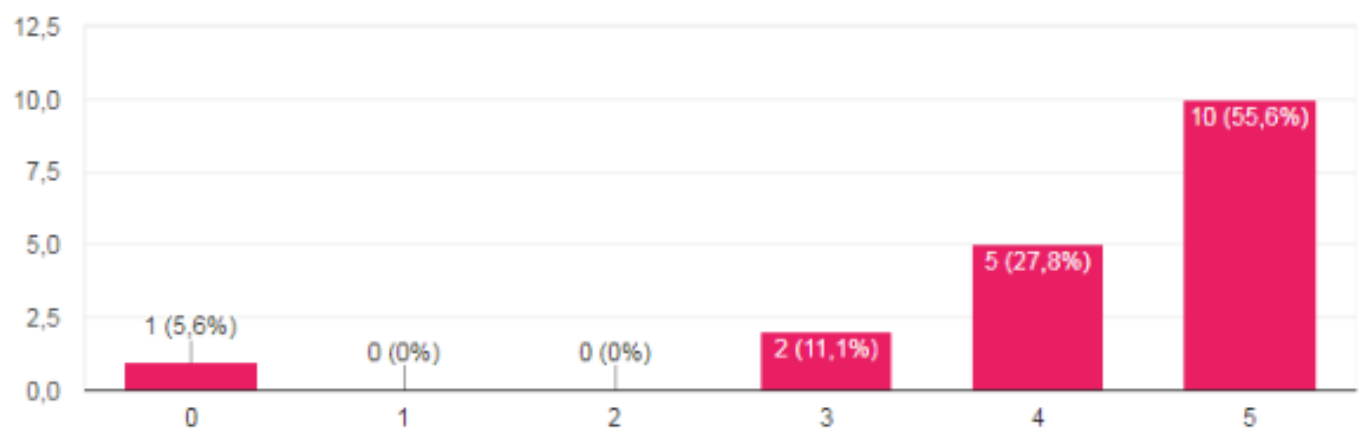

Fonte: Autoria própria

Através da análise do gráfico 5 , vemos que a característica portabilidade do dispositivo é menos relevante, do ponto de vista do consumidor, que as características anteriormente citadas. Sendo considerada como extremamente relevante para cerca de $55,6 \%$.

A oitava pergunta, busca identificar qual importância o cliente daria a característica: Rapidez de funcionamento?

Obtemos com o gráfico 6 que 76,5\% dos entrevistados identificam a característica rapidez de funcionamento como sendo um fator extremamente relevante para o bom funcionamento do ATAEASY, fato que demonstra que essa é uma característica muito relevante para o consumidor do nosso produto.

Gráfico 6: Rapidez de funcionamento.

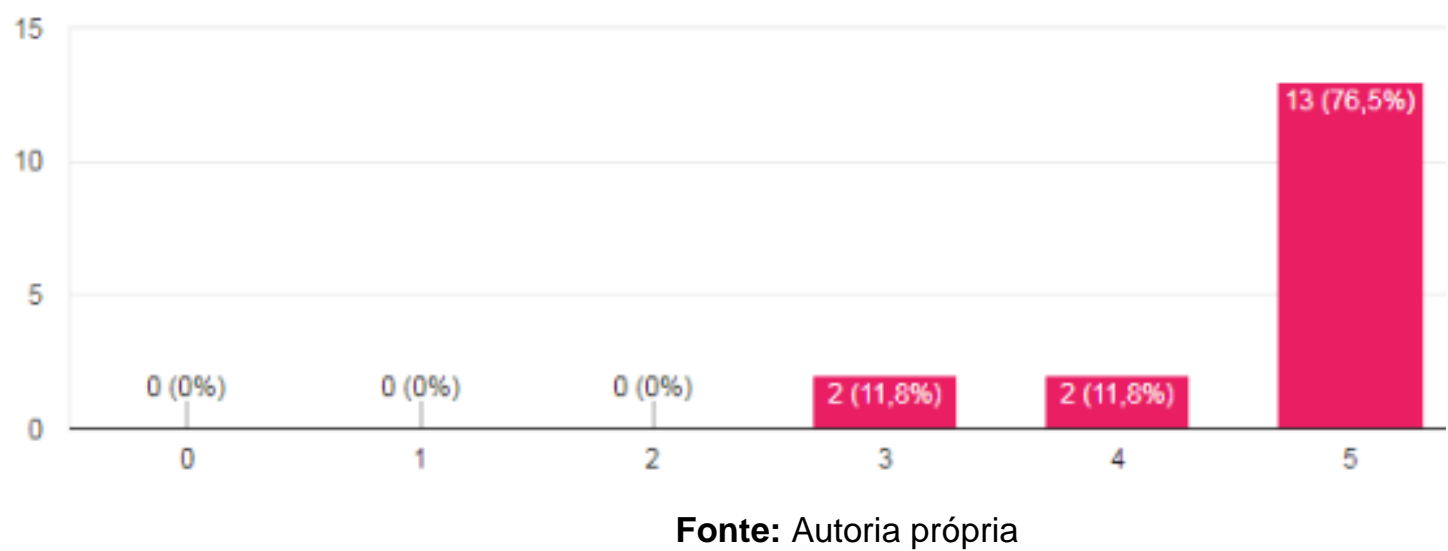


$\mathrm{Na}$ nona os entrevistados poderiam escrever abertamente sobre suas opiniões para contribuir com a construção do produto. Das respostas, obtivemos as seguintes sugestões: reconhecimento de campos de formulário, busca rápida por atas, coesão, coerência e pontuação correta, geração de documento em formato editável, dispositivo de segurança para evitar perdas em caso de falta de energia, qualidade no momento da transcrição do áudio para a escrita e segurança para a proteção do sigilo das informações das atas.

Na décima pergunta, buscamos saber o que os funcionários esperam do produto quanto à estética do dispositivo. Das respostas obtivemos as seguintes sugestões: apresentação similar à de um aparelho de celular, sendo pequeno e portátil, aparência moderna com harmonia entre formas e cores, presença de tela digital.

A pergunta de número 11, perguntava o que as pessoas esperam do produto em relação a ergonomia. Ao analisar as respostas, não obtivemos sugestões relevantes.

$\mathrm{Na}$ décima segunda pergunta, tratamos de saber um pouco sobre o que o cliente mudaria ou acrescentaria no ATAEASY para a sua satisfação. Obtivemos 17 respostas sobre como melhorar o produto para ser utilizado de uma maneira eficiente e eficaz, trazendo como uma delas a simplicidade e a praticidade.

A décima terceira pergunta, aborda o entrevistado quanto à existência de algum campo de informação, além dos citados, que ele considere necessário estar disponível no ATAEASY. Das respostas, extraímos as seguintes sugestões: endereço do local onde aconteceu a reunião e pautas que não foram discutidas.

A décima quarta pergunta retrata um pouco sobre a questão de quem é responsável por secretariar as reuniões das quais os entrevistados participam. 27,8\% dos entrevistados afirmam que geralmente a responsabilidade de redigir as atas das reuniões que eles participam é de técnicos administrativos presentes exclusivamente para a função de secretariar a reunião e cerca de $72,2 \%$ afirmam que são os próprios participantes das reuniões que se responsabilizam pelas atas. Isso significa que em $27,8 \%$ doas casos a instituição precisa dispor do tempo de um servidor para a exclusiva função de redigir atas de reunião e ainda que quando isso não acontece as atas são produzidas por pessoas que talvez não estejam familiarizadas com a formatação de uma ata.

$\mathrm{Na}$ décima quinta pergunta, procuramos saber quando um dos servidores convocados para integrar a reunião fica responsável por secretariar a mesma, o que geralmente acontece com relação à elaboração das atas. $11,1 \%$ dos entrevistados 
afirmam que a ata é produzida durante a reunião e 88,9\% afirmam que a reunião é gravada e a ata é elaborada posteriormente, indicando o dispêndio de tempo dos servidores além do horário de reunião.

$\mathrm{Na}$ última pergunta, questionamos a respeito dos casos em que a ata é produzida durante a própria reunião, se seria possível informar se os servidores necessitam despender tempo extra logo após o término da mesma para concluir a elaboração e fazer ajustes. $72,2 \%$ dos entrevistados afirmam que frequentemente é necessário que o responsável pela elaboração da ata de reunião gaste mais tempo após a mesma para fazer ajustes, dando grande ênfase na necessidade de um redator de atas que facilite esse serviço.

\subsection{ANÁLISE DOS PRODUTOS CONCORRENTES}

Em primeira instância, temos que analisar as funções de cada um dos concorrentes, abordando possível diferença entre o ATAEASY.

Em primeiro lugar, temos o Meeting Minutes Pro, o qual também redige Atas de reunião, insere o nome dos participantes da reunião e exporta a ata para PDF, mas este concorrente não contem uma interface amigável, as legendas são em inglês, além disso registra todos os dados de uma reunião em forma de quadro, formato que não é aceito em muitas instituições.

Em segundo lugar, temos o software One Note que é um programa de computador para o recolhimento de informações, podendo ser utilizado em reuniões, registrando notas do usuário manuscritas ou digitadas, e a captura de comentários de áudio. Ademais, as notas podem ser compartilhadas com outros usuários do One Note através da internet ou por uma rede.

Como terceiro concorrente, temos o gravador de celular, uma vez que muitos dos entrevistados afirmaram que o ATAEASY poderia ser substituído pelo aparelho por meio da gravação de áudio. Contudo, ao gravar uma ata de reunião, o responsável pelo registro da ata teria que despender tempo fazendo a transcrição do que foi gravado, tendo ainda que formatar o documento manualmente, ocasionando um grande desperdício de tempo. Dessa maneira, a produtividade do funcionário é podada, pois seu tempo é desviado de outra função de maior valor agregado para a tarefa de produção de atas de reunião. 


\subsubsection{Matriz QFD}

A matriz QFD será a metodologia adotada para complementar a análise dos concorrentes, realizada na seção anterior, o desdobramento dos requisitos dos clientes em requisitos técnicos de qualidade que devem ser atribuídos ao produto, bem como para identificar a característica de prioridade do ponto de vista do cliente.

Os principais requisitos dos clientes que foram identificados através da pesquisa de marketing feita junto ao público-alvo do dispositivo estão dispostos no quadro 1, na coluna Nível 1, as outras colunas são destinadas ao sucessivo desdobramento desses requisitos em objetivos técnicos.

Quadro 1: Classificação dos requisitos

\begin{tabular}{|c|c|c|}
\hline \multicolumn{3}{|c|}{ Redator automático de atas de reunião - desdobram ento dos requisitos dos clientes } \\
\hline Nivel 1 & Nivel 2 & Nivel 3 \\
\hline Facilidade de utilização & $\begin{array}{c}\text { Permitir a visualização da } \\
\text { navegação }\end{array}$ & Possuir uma interface amigável \\
\hline $\begin{array}{c}\text { Qualidade da transcrição do } \\
\text { comando de voz }\end{array}$ & $\begin{array}{c}\text { Transcrever corretamente o } \\
\text { que foi falado pelo usuário. }\end{array}$ & Possuir um microfone muito bom \\
\hline Rapidez de funcionamento. & $\begin{array}{c}\text { Processar as informações } \\
\text { rapidamente }\end{array}$ & $\begin{array}{c}\text { Possuir um processador com } \\
\text { capacidade de processamento adequada }\end{array}$ \\
\hline Segurança & $\begin{array}{c}\text { Impedir que o sigilo das } \\
\text { informações contidas nas atas } \\
\text { seja quebrado. }\end{array}$ & Possuir senhas de dificil decifração \\
\hline praticidade & $\begin{array}{c}\text { Permitir que fallhas sejam } \\
\text { corrigidas facilmente }\end{array}$ & Gerar arquivos em formato editável \\
\hline
\end{tabular}

Fonte: Autoria própria

O ATAEASY foi comparado com três concorrentes mais próximos, que são o aplicativo Meeting Minutes Pro (concorrente A), disponível na Google Play pelo preço de $\mathrm{R} \$ 10,99$; o software one Note (concorrente B) do pacote de programas da Microsot@, e com o gravador de celular (concorrente $\mathrm{C}$ ), que foi apontado nas pesquisas como substituto para o ATAEASY por nove dos dezoito entrevistados.

Para utilizar a matriz QFD, inserimos os requisitos essenciais para a qualidade do ATAEASY em nível 3, obtidos através do Quadro 1. Cada uma dessas características deverá estar associada a uma característica técnica e mensurável situada em uma das colunas da matriz QFD. A interseção entres as linhas e colunas contém um índice que indica a correlação entre o requisito na linha e característica técnica na coluna, sendo representado por símbolos: triângulo para forte, quadrado para média e círculo para fraco. 
Além disso, na matriz, pode-se analisar a relação do ATAEASY com os concorrentes $\mathrm{A}, \mathrm{B}$ e $\mathrm{C}$, pois a cada um foi dado uma nota de 0 a 5 , representando 0 desempenho do produto concorrente em relação a cada requisito do cliente. A coluna que contém o grau de importância é destinada a atribuir uma nota entre 0 e 5 de acordo com a importância que o requisito tem para o cliente. A coluna produto da empresa foi utilizada para indicar como o processo atual de redação de atas atende seus usuários em relação a cada um dos requisitos listados por eles.

A qualidade planejada representa o nível de qualidade de que pretendemos alcançar com o desenvolvimento do novo produto. O índice de melhoria, é obtido através de uma divisão entre a qualidade planejada e o produto da empresa. $\mathrm{O}$ argumento de vendas é encontrado dividindo a qualidade planejada pelo concorrente de maior desempenho em cada requisito. Assim, podemos identificar o peso absoluto que resulta da multiplicação entre as colunas 1, 6 e 7 .

\section{Quadro 2: Matriz QFD}

\begin{tabular}{|c|c|c|c|c|c|c|c|c|c|c|c|c|c|c|c|}
\hline Nível 3 & $\begin{array}{l}\widehat{E} \\
\frac{\bar{c}}{0} \\
\frac{\pi}{0} \\
\frac{0}{0} \\
\frac{0}{0} \\
\frac{0}{0} \\
\frac{\pi}{0} \\
\frac{0}{4}\end{array}$ & 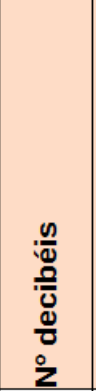 & 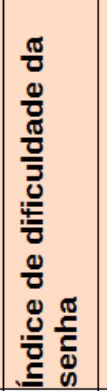 & 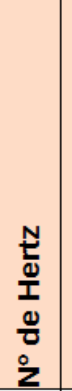 & 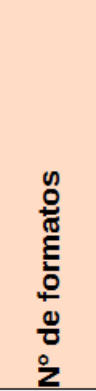 & 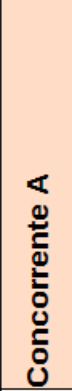 & 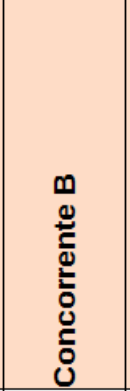 & 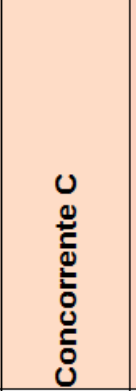 & 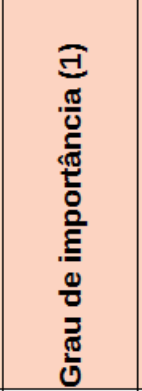 & 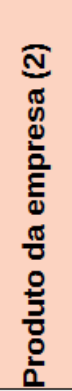 & $\begin{array}{l}\frac{\pi}{0} \\
\frac{\pi}{0} \\
\frac{\pi}{0} \\
\frac{\pi}{\frac{\pi}{\pi}} \\
\frac{\pi}{0} \\
\dot{0}\end{array}$ & 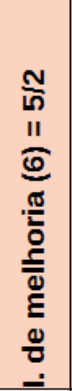 & 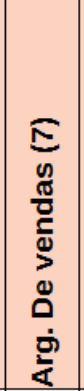 & 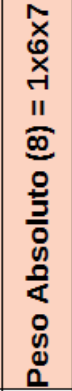 & 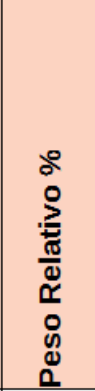 \\
\hline $\begin{array}{c}\text { Possuir uma interface } \\
\text { amigável }\end{array}$ & $\Delta$ & & & & & 5 & 3 & 4 & 4 & 3 & 5 & 1 & 1 & 4 & $10,88 \%$ \\
\hline $\begin{array}{l}\text { Possuir um microfone } \\
\text { muito bom }\end{array}$ & & $\square$ & & & & 4 & 4 & 4 & 5 & NA & 4 & 4 & 1 & 20 & $54,42 \%$ \\
\hline $\begin{array}{l}\text { Possuir um } \\
\text { processador com } \\
\text { capacidade de } \\
\text { processamento } \\
\text { adequada }\end{array}$ & & & & $\square$ & & 4 & 4 & 3 & 3 & 5 & 5 & 1 & 1,25 & 3,75 & $10,20 \%$ \\
\hline $\begin{array}{l}\text { Possuir senha com } \\
\text { alto nivel de } \\
\text { segurança }\end{array}$ & & & & & & 5 & 5 & 2 & 4 & 5 & 5 & 1 & 1 & 4 & $10,88 \%$ \\
\hline $\begin{array}{l}\text { Gerar arquivos em } \\
\text { formato editável }\end{array}$ & & & & & $\triangle$ & 5 & 3 & 3 & 3 & 3 & 5 & 1,67 & 1 & 5 & $13,61 \%$ \\
\hline $\begin{array}{r}\text { Peso Absoluto } \\
\text { Peso Relativo } \\
\end{array}$ & \begin{tabular}{|l|}
43,54 \\
$5,60 \%$ \\
\end{tabular} & \begin{tabular}{|l|}
489,8 \\
$63,0 \%$ \\
\end{tabular} & \begin{tabular}{|c|}
91,84 \\
$11,81 \%$ \\
\end{tabular} & \begin{tabular}{|l|}
98,0 \\
$13 \%$ \\
\end{tabular} & $\begin{array}{l}54,42 \\
7,00 \% \\
\end{array}$ & 777,6 & \begin{tabular}{|l|} 
Relação \\
Forte (x9) \\
\end{tabular} & Fraco (x2) & Médio (x4) & & & & Soma & 36,75 & \\
\hline
\end{tabular}

Fonte: Autoria Própria

A cada requisito pode ser associado um peso relativo, calculando sua porcentagem em relação ao total dos pesos absolutos, esse peso relativo, multiplicado pelo nível de correlação que cada requisito tem com cada um dos atributos técnicos nos permite 
visualizar, qual o atributo com maior relevância para o cliente. Para o ATAEASY o atributo identificado como mais importante foi o número de decibéis com aproximadamente $63 \%$ de peso. Refletindo a necessidade de uma transcrição de áudio de qualidade. Especial atenção deve ser dada a esse atributo em particular.

\subsection{PROPOSTA DO NOVO PRODUTO}

Com o projeto ATAEASY, objetivamos propor a criação de um dispositivo que facilite a criação de atas de reuniões, evitando que o cliente perca tempo digitando a mesma. O produto será comandado por um software que captura o áudio e transcreverá para um formato de ata automaticamente, e com opções de exportar a ata em formato PDF ou editável para permitir alterações necessárias.

O software do equipamento foi programado em linguagem Java SE através do ambiente de desenvolvimento integrado (IDE, do inglês Integrated Development Environment) NetBeans Community - Eddition 8.2.

A seguir, é apresentado um esboço do ATAEASY. Na figura, temos à esquerda o receptor de áudio, responsável pela captação da voz, à direita o botão bifuncional, o qual liga e desliga, abaixo dele se encontram dois conectores USB. Na parte superior, observa-se, display touchscreen. A representação abaixo foi desenvolvida por meio do aplicativo de desenho industrial 3D sketchup.

Figura 1: Delineamento do redator de atas automático: ATAEASY

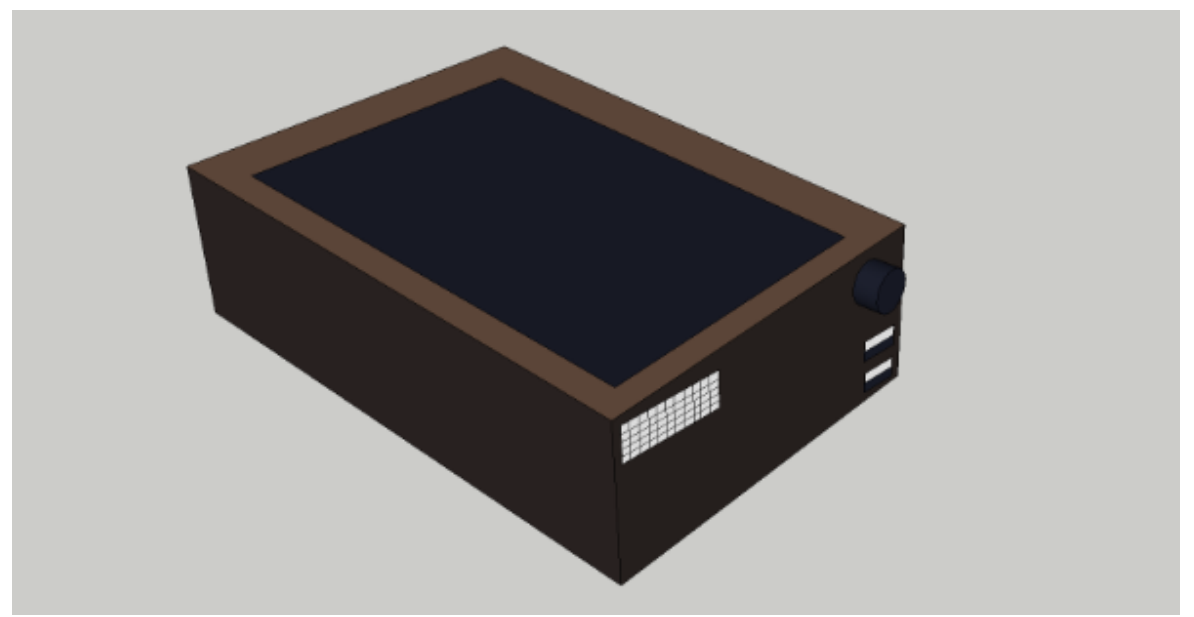

Fonte: Autoria própria

Para realizar a montagem do protótipo do produto ATAEASY foram listados, inicialmente, 6 componentes associados, descritos através da tabela 1, acompanhado de suas estimativas de preço. 
Tabela 1: Orçamento do equipamento ATAEASY

\begin{tabular}{cc}
\hline \multicolumn{2}{c}{ ORÇAMENTO DO PRODUTO } \\
\hline ITEM & PREÇO (RS) \\
\hline Raspberry PI3 Model B & 198,90 \\
SD Card Classe 10,8 GB & 20,00 \\
Geekworm UPS Hat Board + & 77,17 \\
2500 mAh & \\
5 inch Capacitive Touch LCD & 59,99 \\
800x480 & 105,87 \\
ReSpeaker 2-Mics Pi HAT & 461,93 \\
TOTAL &
\end{tabular}

Fonte: Autoria própria.

\subsubsection{FMEA}

A ferramenta FMEA foi aplicada nesse trabalho a fim de antecipar os tipos de falhas que podem surgir durante a utilização do ATAEASY. Através da sua aplicação, percebe-se que os defeitos que podem surgir estão associados ao botão de ligar/desligar, microfone do aparelho, tela touch screen e processador.

Quadro 3: Análise da ocorrência de falhas

\begin{tabular}{|c|c|c|c|c|c|c|c|c|c|}
\hline \multirow{2}{*}{ FMEA } & & \multicolumn{3}{|c|}{ Projeto do produto } & $\square$ & \multicolumn{4}{|c|}{ Processo } \\
\hline & 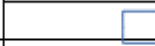 & \multicolumn{3}{|c|}{ Revisão de projeto do produto } & & \multicolumn{4}{|c|}{ Revisão de processo } \\
\hline Processo/produto & \multicolumn{9}{|c|}{ ATAEASY } \\
\hline Aplicação & \multicolumn{9}{|c|}{ Redator de atas automático } \\
\hline Áreas envolvidas & \multicolumn{9}{|c|}{ Gestão da produção Industrial / Gestão da qualidade } \\
\hline \multirow{3}{*}{ ITEM } & \multirow{3}{*}{\begin{tabular}{|c|} 
Nome do \\
componente \\
de processo \\
\end{tabular}} & \multirow{2}{*}{\multicolumn{3}{|c|}{\begin{tabular}{c|c} 
Data de elaboração & $10 / 02 / 19$ \\
\multicolumn{2}{c}{ Possiveis falhas }
\end{tabular}}} & \multirow{2}{*}{\multicolumn{5}{|c|}{\begin{tabular}{|c|} 
Atual \\
ÍNDICES \\
\end{tabular}}} \\
\hline & & & & & & & & & \\
\hline & & MODO & EFEITO & CAUSA(S) & Controles & 0 & $\mathbf{G}$ & D & $\mathbf{R}$ \\
\hline \multirow[t]{2}{*}{1} & $\begin{array}{c}\text { Botão } \\
\text { liga/desliga }\end{array}$ & Inutilizável & \begin{tabular}{|c|} 
Dificuldade \\
ao ligar o \\
ATAEA SY
\end{tabular} & Desgaste & $\begin{array}{c}\text { Substituição } \\
\text { por um } \\
\text { botão novo }\end{array}$ & 7 & 8 & 3 & 168 \\
\hline & & Inutilizável & $\begin{array}{c}\text { Dificuldade } \\
\text { ao ligar o } \\
\text { A TAEA SY }\end{array}$ & $\begin{array}{c}\text { pressão } \\
\text { exacerbada } \\
\text { ao ligar no } \\
\text { botão }\end{array}$ & $\begin{array}{l}\text { Treinamento } \\
\text { do manuseio }\end{array}$ & 6 & 5 & 6 & 180 \\
\hline 2 & Microfone & Áudio baixo & $\begin{array}{c}\text { Incoerência } \\
\text { da ata }\end{array}$ & $\begin{array}{l}\text { Distância } \\
\text { alta do } \\
\text { redator }\end{array}$ & $\begin{array}{l}\text { Manuseio } \\
\text { correto }\end{array}$ & 4 & 7 & 2 & 56 \\
\hline \multirow[t]{2}{*}{3} & $\begin{array}{l}\text { Touch } \\
\text { screen }\end{array}$ & $\begin{array}{l}\text { Touch } \\
\text { travando }\end{array}$ & \begin{tabular}{|c|} 
Impossibilid \\
ade de \\
utilização \\
\end{tabular} & $\begin{array}{c}\text { Excesso de } \\
\text { uso }\end{array}$ & $\begin{array}{c}\text { Reiniciar o } \\
\text { aparelho }\end{array}$ & 8 & 7 & 7 & 392 \\
\hline & & $\begin{array}{l}\text { Touch } \\
\text { travando }\end{array}$ & $\begin{array}{l}\text { Defeito de } \\
\text { hardware }\end{array}$ & Mal contato & $\begin{array}{c}\text { Substituição } \\
\text { por uma tela } \\
\text { nova }\end{array}$ & 5 & 7 & 6 & 210 \\
\hline 4 & Processador & $\begin{array}{l}\text { A parelho } \\
\text { travando }\end{array}$ & $\begin{array}{c}\text { Sistema } \\
\text { corrompido }\end{array}$ & $\begin{array}{c}\text { Queda de } \\
\text { desempenho }\end{array}$ & $\begin{array}{c}\text { Restaurar o } \\
\text { aparelho }\end{array}$ & 3 & 6 & 4 & 72 \\
\hline
\end{tabular}

Fonte: Autoria própria. 
Dessa forma, através dos resultados do FMEA pode-se tomar decisões e atitudes cabíveis para eliminar ou reduzir falhas do ATAEASY, objetivando melhorar a experiência do consumidor com o equipamento.

Por exemplo, se considerarmos o modo de falha do componente botão liga/desliga que pode se tornar inutilizável devido ao excesso de pressão aplicada no mesmo, podemos pensar em uma medida simples como um adesivo de proteção que venha a ser colado sobre o botão do aparelho novo, para que antes de removê-lo o consumidor seja alertado de que o excesso de pressão sobre aquele componente pode levar à sua posterior inutilização.

Além dessas informações, o FMEA ainda traz os valores que retratam o índice de ocorrência - (O), gravidade (G) e detecção - (D), sendo essas índices representados através de um número, que pode variar entre 1 e 10. Para o índice, ocorrência, o número 1 significa que o modo de falha tem probabilidade de quase nunca ocorrer e o número 10 representa alta probabilidade de ocorrência.

$\mathrm{Na}$ escala do índice de gravidade, o número 1 significa que o modo de falha tem baixa gravidade e o número 10 representa alta gravidade. Através da escala do índice de detecção podemos analisar se o modo de falha poder ser de fácil observação, onde 1 significa baixa probabilidade de detecção pelo usuário e 10 significa alta possibilidade de detecção.

A letra $\mathrm{R}$ representa o resultado da multiplicação dos índices de ocorrência, gravidade e detecção. O valor encontrado pode ser interpretado como o grau de impacto do modo de falha na utilização do equipamento, pelo consumidor. Por isso, quanto maior o seu valor, maior atenção deve ser dada ao item em questão.

\section{CONSIDERAÇOES FINAIS}

O presente trabalho destinou-se ao projeto de um equipamento destinado a satisfazer as necessidades de funcionários de universidades, instituições e até mesmo escolas, auxiliando na elaboração de atas de maneira eficiente e eficaz, diminuindo o tempo gasto com trabalho repetitivo. Assim, foi idealizado um equipamento capaz de formular atas de reunião por meio do acionamento por comando de voz e com a funcionalidade de exportar o documento redigido em formato editável (docx), através do software do produto. 
Através das pesquisas realizadas junto ao público-alvo do produto, concluímos que há interesse nas funcionalidades projetadas para o ATAEASY, contudo no decorrer da pesquisa passamos a entender que a oferta de um produto composto por hardware e software pode não ser a opção mais viável, devido ao custo orçado dos componentes, que ficou estimada em $\mathrm{R} \$ 461,93$. Em adição ao alto custo orçado para o produto, tem-se o fato da ampla difusão do acesso a computadores e dispositivos móveis como celulares e tablets, tal fator indica a possibilidade de que a versão apenas em software do ATAEASY poderia ser mais viável do que a sua versão em equipamento físico.

Por fim, concluímos que os objetivos da presente pesquisa foram alcançados e que o projeto de desenvolvimento de um redator automático de atas de reunião acionado por comando de voz que foi elaborado reflete as necessidades de seu público-alvo e tem potencial de facilitar o cotidiano de trabalho de muitas pessoas. Como sugestão para trabalhos futuros deixamos a elaboração de um software baseado nos requisitos levantados durante o desenvolvimento dessa pesquisa.

\section{REFERÉNCIAS}

ABREU, Fábio de Souza. QFD - Quality Function Deployment Requisitos

Organizacionais para Aplicação. 2007. 310 f. Monografia (Especialização) - Curso de Mercadologia, Eaesp/fgv, Eaesp/fgv, São Paulo, 200. Disponível em <file:///C:/Users/ifto/Downloads/1199700764.pdf> Acesso em 17 de Maio 2018.

BAXTER, Mike. Projeto de produto: Guia prático para o design de novos produtos. 2. ed. São Paulo: Editora Blucher, 2000. (5). Disponível em $<$ file:///D:/Projeto\%20de\%20Produto\%20(Mike\%20Baxter)\%20CRDuarte.pdf > Acesso em 17/05/2018 às 15:02.

CHENG, L.C. Visão geral do desdobramento da função qualidade (QFD). In: CHENG et al. QFD: planejamento da qualidade. Belo Horizonte: Líttera Maciel, 1995. cap. 2, p. 1954.

CLARK, K.B.; FUJIMOTO, T. Product development performance: strategy, organization and management in the world auto industry. Boston-Mass., Harvard Business School Press, 1991.

GÜNTHER, Hartmut. Pesquisa Qualitativa Versus Pesquisa Quantitativa: Esta É a Questão? Teoria, Brasilia, v. 22, n. 2, p.201-210, 7 ago. 2006. Disponível em $<$ http://www.scielo.br/pdf/ptp/v22n2/a10v22n2>. Acesso em 17 de Maio 2018. 
ZORZAN, F. et al. FMEA: orientações conceituais para a aplicação de uma ferramenta de antecipação de falhas. In: Semana Internacional das Engenharias da Fahor (SIEF), 3. 2013, Horizontina. Anais... Horizontina: Fahor. 